

\title{
SPECTRAL ELEMENT MODEL FOR THE VIBRATION OF A SPINNING TIMOSHENKO SHAFT
}

\author{
USIK LEE AND INJOON JANG
}

\begin{abstract}
A spectral element model for a spinning uniform shaft is developed. The spinning shaft supported by bearings is represented by the uniform Timoshenko beam model and the bearing-supports are represented by equivalent springs. The variational approach is used to formulate the spectral element model by using the frequency-dependent shape functions derived from exact wave solutions on the frequency-domain governing differential equations. The conventional finite element model is also formulated for evaluating the accuracy of the present spectral element model through some example problems.
\end{abstract}

\section{Introduction}

Spinning shafts have been extensively used in diverse engineering applications such as motors, engines, turbines, and machine tools. In general, the rotating machines consist of multiple spinning shafts and disks (or blades) which are connected to each other to form rotor systems supported by multiple bearings. As it is very important to predict the dynamic characteristics of the rotor systems accurately in the early design phase, there have been extensive studies on the modeling and analysis of such rotor systems in past decades [Nelson 2003].

In previous studies, the dynamics of spinning shafts were represented by various models. When the diameter of a shaft is large relative to its length and when vibration occurs at high frequencies, deflections due to transverse shear and rotary inertia become important. Thus, many researchers have used the Timoshenko beam models for spinning shafts [Eshleman and Eubanks 1969; Nelson 1980; Ehrich 1992; $\mathrm{Zu}$ and Han 1992; Ghoneim and Lawrie 2007; Chen 2010]. In this study, we adopt the Timoshenko beam model used by [Ehrich 1992; Zu and Han 1992].

The early methods used to determine the critical speed of a rotor are Rayleigh's method, Dunkerley's formula, Holzer's method, and the transfer matrix method [Lund 1974]. As the size of the transfer matrix generated to represent a rotor system is not large, the transfer matrix method is very efficient for the analysis of one-dimensional (1D) systems such as rotor systems. However, as the transfer matrix method provides dynamic responses only at the endpoints of a 1D system, postprocessing is necessary to compute the dynamic responses at the interim positions of the system. [Ruhl and Booker 1972] and [Nelson 1980] used FEM to investigate the stability and dynamics of rotor systems. In general, a large number of degrees of freedom (DOFs) are required for an FEM model of a large flexible rotor system, which may result in an increase in the computational cost as well as a widely spread frequency spectrum

This research was supported in part by the Basic Science Research Program through the National Research Foundation of Korea funded by the Ministry of Education, Science and Technology (2010-0007741) and in part by an Inha University research grant.

Keywords: spinning Timoshenko shaft, spectral element model, finite element model, natural frequency, critical speed,

dispersion curve. 
which may include many insignificant vibration modes. To cope with these problems, reduced-order modeling techniques have been introduced [Kane and Torby 1991]. Though reduced-order modeling techniques are useful for reducing the size of FEM models, they are known to degrade the accuracy of FEM solutions.

Thus, as an alternative analysis method, this paper adopts the spectral element method (SEM) for the dynamic analysis of the flexible spinning shafts of a rotor system. SEM may meet two requirements: high accuracy up to the frequency range of interest and the use of a minimum number of DOFs [Doyle 1997; Lee et al. 2000; Vinod et al. 2007; Lee 2009]. Thus, SEM has apparent advantages over the other solution methods such as the transfer matrix method and FEM, especially when it is applied to 1D structural dynamic problems such as rotor systems as well as to structural health monitoring problems. However, though SEM can be also used for nonlinear analysis by using an iterative approach [Lee 2009], conventional FEM can be more efficiently used for nonlinear analysis.

Thus, the purposes of this paper are:

- to develop a spectral element model for the spinning Timoshenko shaft (T-shaft) and

- to apply the spectral element model to investigate the natural frequencies and critical speeds of example spinning shafts.

The results obtained by using the spectral element model are then compared with the results obtained by using the conventional finite element model and the analytical theories available in the literature to verify the accuracy of the spectral element model.

\section{Governing equations}

Consider a spinning flexible uniform shaft subjected to transverse vibrations and represent it as a spinning uniform T-shaft. The equations of motion and relevant boundary conditions for the spinning uniform Tshaft can be derived by using Hamilton's principle [Meirovitch 1980]:

$$
\int_{t_{1}}^{t_{2}}(\delta T-\delta U+\delta W) d t=0,
$$

where $T$ is the kinetic energy, $U$ is the potential energy, and $\delta W$ is the virtual work done by external forces and moments. As shown in Figure 1, the uniform T-shaft of circular cross-section is spinning about the central axis $x$ at a constant speed of $\Omega$ radians/s and it has length $L$, bending rigidity $E I$, transverse shear rigidity $\kappa G A$, mass per length $\rho A$, mass moment of inertia about the $y$ or $z$-axes $\rho I$, and polar mass moment of inertia about the $x$-axis $\rho J$. In Figure 1a, $v(x, t)$ is the transverse displacement in the $y$-direction, $w(x, t)$ is the transverse displacement in the $z$-direction, $\phi(x, t)$ is the rotation angle about the $y$-axis, and $\psi(x, t)$ is the rotation angle about the $z$-axis.

Assuming that the uniform T-shaft takes small amplitude transverse vibrations in the $y$ and $z$-directions, the kinetic and potential energies can be obtained as [Nelson 1980; Ehrich 1992]

$$
\begin{aligned}
& T=\frac{1}{2} \int_{0}^{L} \rho A\left(\dot{v}^{2}+\dot{w}^{2}\right) d x+\frac{1}{2} \int_{0}^{L} \rho I\left(\dot{\phi}^{2}+\dot{\psi}^{2}\right) d x+\frac{1}{2} \int_{0}^{L} \rho J(\Omega-\phi \dot{\psi})^{2} d x \\
& U=\frac{1}{2} \int_{0}^{L} E I\left(\phi^{\prime 2}+\psi^{\prime 2}\right) d x+\frac{1}{2} \int_{0}^{L} \kappa G A\left[\left(v^{\prime}-\psi\right)^{2}+\left(w^{\prime}+\phi\right)^{2}\right] d x+\sum_{i=1}^{2} \frac{1}{2} \boldsymbol{v}_{i}^{T} \boldsymbol{K}_{\text {support }(i)} \boldsymbol{v}_{i},
\end{aligned}
$$



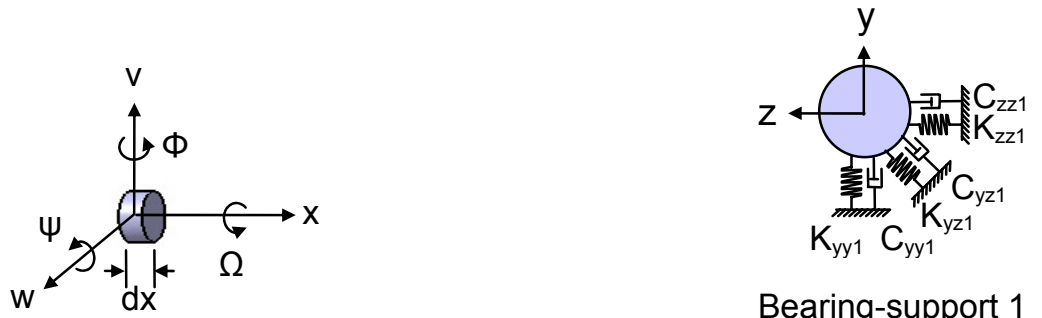

Bearing-support 1

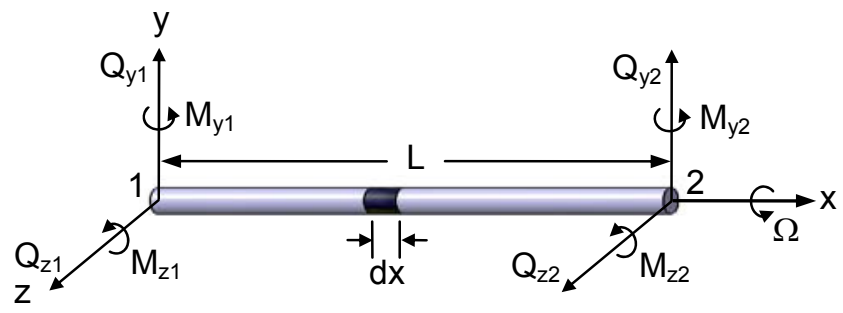

(a)

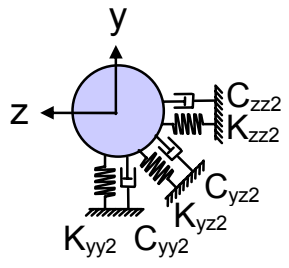

Bearing-support 2

(b)

Figure 1. A spinning uniform shaft: (a) displacement fields and the boundary forces and moments and (b) bearing-supports.

where

$$
\boldsymbol{v}_{i}=\left\{\begin{array}{c}
v_{i} \\
w_{i}
\end{array}\right\}, \quad \boldsymbol{K}_{\operatorname{support}(i)}=\left[\begin{array}{cc}
K_{y y i} & K_{y z i} \\
K_{z y i} & K_{z z i}
\end{array}\right] \quad(i=1,2)
$$

The matrices $\boldsymbol{K}_{\text {support(1) }}$ and $\boldsymbol{K}_{\text {support(2) }}$ represent the stiffnesses of bearing-supports 1 and 2, as shown in Figure $1 \mathrm{~b}$, and the vectors $\boldsymbol{v}_{1}$ and $\boldsymbol{v}_{2}$ represent the transverse displacements at bearing-supports 1 and 2. The $\operatorname{dot}\left({ }^{\circ}\right)$ and prime $\left({ }^{\prime}\right)$ denote the derivatives with respect to the time $t$ and axial coordinate $x$, respectively. In (2), the first integral represents the translational kinetic energy and the other two integrals the rotational kinetic energies. In (3), the first integral represents the strain energy for the transverse bending deformations, the second integral for the transverse shear deformations, and the last term for the bearing-support deformations. The virtual work $\delta W$ is given by

$$
\begin{aligned}
\delta W=\int_{0}^{L}\left(p_{y} \delta v\right. & \left.+p_{z} \delta w+\tau_{y} \delta \phi+\tau_{z} \delta \psi\right) d x+Q_{y 1} \delta v_{1}+Q_{y 2} \delta v_{2}+Q_{z 1} \delta w_{1}+Q_{z 2} \delta w_{2} \\
& +M_{y 1} \delta \phi_{1}+M_{y 2} \delta \phi_{2}+M_{z 1} \delta \psi_{1}+M_{z 2} \delta \psi_{2}-f_{\dot{v}_{1}} \delta v_{1}-f_{\dot{w}_{1}} \delta w_{1}-f_{\dot{v}_{2}} \delta v_{2}-f_{\dot{w}_{2}} \delta w_{2}
\end{aligned}
$$

where $Q_{y i}, Q_{z i}, M_{y i}$, and $M_{z i}(i=1,2)$ are the transverse shear forces and bending moments applied at the two ends of the T-shaft as shown in Figure 1a. The forces and bending moments distributed along the $x$-axis are $p_{y}, p_{z}, \tau_{y}$, and $\tau_{z}$. The viscous damping forces generated by bearing-supports 1 and 2 are $f_{\dot{v}_{i}}$ and $f_{\dot{w}_{i}}(i=1,2)$, and they can be computed from

$$
f_{\dot{v}_{i}}=\frac{\partial R}{\partial_{\dot{v}_{i}}}, \quad f_{\dot{w}_{i}}=\frac{\partial R}{\partial \dot{w}_{i}} \quad(i=1,2) .
$$


The Rayleigh's dissipation function $R$ is given by

$$
R=\sum_{i=1}^{2} \frac{1}{2} \dot{\boldsymbol{v}}_{i}^{T} \boldsymbol{C}_{\text {support }(i)} \dot{\boldsymbol{v}}_{i}
$$

where

$$
\boldsymbol{C}_{\text {support }(i)}=\left[\begin{array}{ll}
C_{y y i} & C_{y z i} \\
C_{z y i} & C_{z z i}
\end{array}\right] \quad(i=1,2),
$$

where $C_{a b i}(a, b=y, z)$ are viscous damping coefficients of the bearing-supports as shown in Figure $1 \mathrm{~b}$.

Substituting (2), (3), and (6) into (1) and then applying the integral by parts, we can obtain the differential equations of motion as

$$
\begin{aligned}
\rho A \ddot{v}-\kappa G A\left(v^{\prime \prime}-\psi^{\prime}\right) & =p_{y}, & \rho I \ddot{\psi}-\rho J \Omega \dot{\phi}-E I \psi^{\prime \prime}-\kappa G A\left(v^{\prime}-\psi\right)+\rho J\left(2 \phi \dot{\phi} \dot{\psi}+\phi^{2} \ddot{\psi}\right) & =\tau_{z}, \\
\rho A \ddot{w}-\kappa G A\left(w^{\prime \prime}+\phi^{\prime}\right) & =p_{z}, & \rho I \ddot{\phi}+\rho J \Omega \dot{\psi}-E I \phi^{\prime \prime}+\kappa G A\left(w^{\prime}+\phi\right)-\rho J \phi \dot{\psi}^{2} & =\tau_{y},
\end{aligned}
$$

and the natural boundary conditions as

$$
\begin{gathered}
Q_{y}(0, t)=K_{y y 1} v_{1}+\frac{1}{2}\left(K_{y z 1}+K_{z y 1}\right) w_{1}+C_{y y 1} \dot{v}_{1}+\frac{1}{2}\left(C_{y z 1}+C_{z y 1}\right) \dot{w}_{1}-Q_{y 1}, \\
Q_{y}(L, t)=-K_{y y 2} v_{2}-\frac{1}{2}\left(K_{y z 2}+K_{z y 2}\right) w_{2}-C_{y y 2} \dot{v}_{2}-\frac{1}{2}\left(C_{y z 2}+C_{z y 2}\right) \dot{w}_{2}+Q_{y 2}, \\
Q_{z}(0, t)=K_{z z 1} w_{1}+\frac{1}{2}\left(K_{y z 1}+K_{z y 1}\right) v_{1}+C_{z z 1} \dot{w}_{1}+\frac{1}{2}\left(C_{y z 1}+C_{z y 1}\right) \dot{v}_{1}-Q_{z 1}, \\
Q_{z}(L, t)=-K_{z z 2} w_{2}-\frac{1}{2}\left(K_{y z 2}+K_{z y 2}\right) v_{2}-C_{z z 2} \dot{w}_{2}-\frac{1}{2}\left(C_{y z 2}+C_{z y 2}\right) \dot{v}_{2}+Q_{z 2}, \\
M_{y}(0, t)=-M_{y 1}, \quad M_{y}(L, t)=M_{y 2}, \\
M_{z}(0, t)=-M_{z 1}, \quad M_{z}(L, t)=M_{z 2} .
\end{gathered}
$$

The force-displacement relations are defined by

$$
\begin{array}{ll}
Q_{y}(x, t)=\kappa G A\left(v^{\prime}-\psi\right), & M_{y}(x, t)=E I \phi^{\prime}, \\
Q_{z}(x, t)=\kappa G A\left(w^{\prime}+\phi\right), & M_{z}(x, t)=E I \psi^{\prime} .
\end{array}
$$

By neglecting small nonlinear terms from (9), we can obtain

$$
\begin{aligned}
\rho A \ddot{v}-\kappa G A\left(v^{\prime \prime}-\psi^{\prime}\right) & =p_{y}, & & \rho I \ddot{\psi}-\rho J \Omega \dot{\phi}-E I \psi^{\prime \prime}-\kappa G A\left(v^{\prime}-\psi\right)=\tau_{z}, \\
\rho A \ddot{w}-\kappa G A\left(w^{\prime \prime}+\phi^{\prime}\right) & =p_{z}, & & \rho I \ddot{\phi}+\rho J \Omega \dot{\psi}-E I \phi^{\prime \prime}+\kappa G A\left(w^{\prime}+\phi\right)=\tau_{y} .
\end{aligned}
$$

Equations (12) are identical to the governing equations introduced in [Ehrich 1992; Zu and Han 1992]. Equations (12) will be used herein for developing a spectral element model for spinning T-shafts.

\section{Spectral element modeling}

The spectral element model for the spinning uniform T-shaft is derived from the differential equations of motion given by (12). To formulate the spectral element, we represent the solutions of (12), the external forces, and the resultant forces and moments in spectral forms as [Lee 2009]

$$
\{v(x, t) w(x, t) \psi(x, t) \phi(x, t)\}=\frac{1}{N} \sum_{n=0}^{N-1}\left\{V_{n}\left(x ; \omega_{n}\right) W_{n}\left(x ; \omega_{n}\right) \psi_{n}\left(x ; \omega_{n}\right) \phi_{n}\left(x ; \omega_{n}\right)\right\} e^{i \omega_{n} t},
$$




$$
\begin{aligned}
& \left\{p_{y}(x, t) \quad p_{z}(x, t) \tau_{y}(x, t) \tau_{z}(x, t)\right\}=\frac{1}{N} \sum_{n=0}^{N-1}\left\{P_{y n}\left(x ; \omega_{n}\right) P_{z n}\left(x ; \omega_{n}\right) T_{y n}\left(x ; \omega_{n}\right) T_{z n}\left(x ; \omega_{n}\right)\right\} e^{i \omega_{n} t}, \\
& \left\{Q_{y}(x, t) \quad Q_{z}(x, t) \quad M_{y}(x, t) M_{z}(x, t)\right\} \\
& =\frac{1}{N} \sum_{n=0}^{N-1}\left\{Q_{y n}\left(x ; \omega_{n}\right) Q_{z n}\left(x ; \omega_{n}\right) M_{y n}\left(x ; \omega_{n}\right) M_{z n}\left(x ; \omega_{n}\right)\right\} e^{i \omega_{n} t} .
\end{aligned}
$$

Substituting (13) and (14) into (12) gives

$$
\begin{gathered}
\kappa G A\left(V^{\prime \prime}-\psi^{\prime}\right)+\rho A \omega^{2} V+P_{y}=0, \quad E I \psi^{\prime \prime}+i \omega \Omega \rho J \Phi+\kappa G A\left(V^{\prime}-\psi\right)+\rho I \omega^{2} \psi+T_{z}=0, \\
\kappa G A\left(W^{\prime \prime}+\Phi^{\prime}\right)+\rho A \omega^{2} W+P_{z}=0, \quad E I \Phi^{\prime \prime}-i \omega \Omega \rho J \psi-\kappa G A\left(W^{\prime}+\Phi\right)+\rho I \omega^{2} \Phi+T_{y}=0,
\end{gathered}
$$

where the subscripts $n$ are omitted for brevity. Similarly, substituting (13) and (15) into (11) gives

$$
\begin{array}{ll}
Q_{y}(x)=\kappa G A\left(V^{\prime}-\psi\right), & M_{y}(x)=E I \Phi^{\prime}, \\
Q_{z}(x)=\kappa G A\left(W^{\prime}+\Phi\right), & M_{z}(x)=E I \psi^{\prime} .
\end{array}
$$

Consider the homogeneous equations reduced from (16) as

$$
\begin{aligned}
\kappa G A\left(V^{\prime \prime}-\psi^{\prime}\right)+\rho A \omega^{2} V & =0, & E I \psi^{\prime \prime}+i \omega \Omega \rho J \Phi+\kappa G A\left(V^{\prime}-\psi\right)+\rho I \omega^{2} \psi & =0, \\
\kappa G A\left(W^{\prime \prime}+\Phi^{\prime}\right)+\rho A \omega^{2} W & =0, & E I \phi^{\prime \prime}-i \omega \Omega \rho J \psi-\kappa G A\left(W^{\prime}+\Phi\right)+\rho I \omega^{2} \Phi & =0 .
\end{aligned}
$$

Assume the homogeneous solutions of (18) as

$$
V(x)=a e^{-i k x}, \quad W(x)=t a e^{-i k x}, \quad \psi(x)=r a e^{-i k x}, \quad \Phi(x)=t \hat{r} a e^{-i k x} .
$$

Substitution of (19) into (18) yields an eigenvalue problem as

$$
\left[\begin{array}{cccc}
\sigma_{1} & -\sigma_{3} & 0 & 0 \\
\sigma_{3} & \sigma_{2} & 0 & -\sigma_{4} \\
0 & 0 & \sigma_{1} & \sigma_{3} \\
0 & \sigma_{4} & -\sigma_{3} & \sigma_{2}
\end{array}\right]\left\{\begin{array}{c}
1 \\
r \\
t \\
t \hat{r}
\end{array}\right\}=\left\{\begin{array}{l}
0 \\
0 \\
0 \\
0
\end{array}\right\}
$$

where

$$
\sigma_{1}=k^{2} \kappa G A-\omega^{2} \rho A, \quad \sigma_{2}=k^{2} E I+\kappa G A-\omega^{2} \rho I, \quad \sigma_{3}=i k \kappa G A, \quad \sigma_{4}=i \omega \Omega \rho J
$$

From (20), we can get a dispersion equation as

$$
\begin{aligned}
& k^{8}-2\left(\eta_{1} k_{F}^{4}+k_{G}^{4}\right) k^{6}+\left(\eta_{1}^{2} k_{F}^{8}+4 \eta_{1} k_{G}^{4} k_{F}^{4}+k_{G}^{8}-2 k_{F}^{4}-\eta_{2}^{-2} \eta_{3}^{2} \Omega^{2} \omega^{2}\right) k^{4} \\
&+\left(-2 \eta_{1}^{2} k_{G}^{4} k_{F}^{8}-2 \eta_{1} k_{G}^{8} k_{F}^{4}+2 \eta_{1} k_{F}^{8}+2 k_{F}^{4} k_{G}^{4}+2 k_{F}^{4} \eta_{2}^{-1} \eta_{3}^{2} \Omega^{2} \omega^{2}\right) k^{2} \\
&+\eta_{1}^{2} k_{G}^{8} k_{F}^{8}-2 \eta_{1} k_{G}^{4} k_{F}^{8}+\left(1-\eta_{3}^{2} \Omega^{2} \omega^{2}\right) k_{F}^{8}=0
\end{aligned}
$$

where

$$
k_{F}=\sqrt{\omega}\left(\frac{\rho A}{E I}\right)^{1 / 4}, \quad k_{G}=\sqrt{\omega}\left(\frac{\rho A}{\kappa G A}\right)^{1 / 4}, \quad \eta_{1}=\frac{\rho I}{\rho A}, \quad \eta_{2}=\frac{E I}{\kappa G A}, \quad \eta_{3}=\frac{\rho J}{\kappa G A} .
$$


Eight wavenumbers $k_{i}(i=1,2, \ldots, 8)$ can be computed from (22). By substituting each wavenumber into (20), we can obtain

$$
\begin{aligned}
r_{j} & =i k_{j}^{-1}\left(k_{G}^{4}-k_{j}^{2}\right), \quad \hat{r}_{j}=-r_{j}, \\
t_{j} & =-\left(i \eta_{3} \Omega \omega\right)^{-1} r_{j}^{-1}\left[i k_{j}+\left(\eta_{2} k_{j}^{2}-\eta_{1} k_{G}^{4}\right) r_{j}\right]
\end{aligned} \quad(j=1,2, \ldots, 8) .
$$

By using the eight wavenumbers computed from (22), the homogeneous solutions of (18) can be obtained as

$$
V(x)=N_{v}(x ; \omega) d, \quad W(x)=N_{w}(x ; \omega) d, \quad \psi(x)=N_{\psi}(x ; \omega) d, \quad \Phi(x)=N_{\phi}(x ; \omega) d .
$$

where

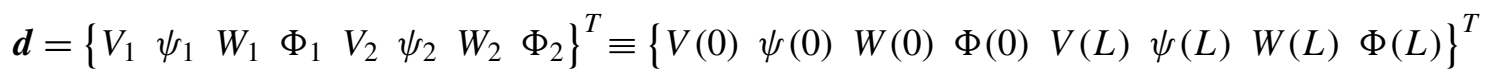

and

$$
\begin{aligned}
\boldsymbol{N}_{v}(x ; \omega) & =\boldsymbol{e}_{v}(x) \boldsymbol{H}_{B}^{-1}, & \boldsymbol{N}_{w}(x ; \omega) & =\boldsymbol{e}_{w}(x) \boldsymbol{H}_{B}^{-1}, \\
\boldsymbol{N}_{\psi}(x ; \omega) & =\boldsymbol{e}_{\psi}(x) \boldsymbol{H}_{B}^{-1}, & \boldsymbol{N}_{\phi}(x ; \omega) & =\boldsymbol{e}_{\phi}(x) \boldsymbol{H}_{B}^{-1},
\end{aligned}
$$

with the use of the following definitions:

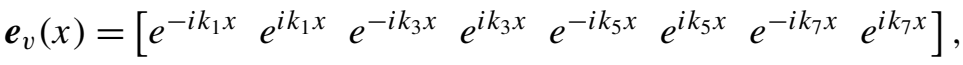

$$
\begin{aligned}
& \boldsymbol{e}_{\psi}(x)=\boldsymbol{e}_{v}(x) \boldsymbol{R}, \quad \boldsymbol{e}_{w}(x)=\boldsymbol{e}_{v}(x) \boldsymbol{T}, \quad \boldsymbol{e}_{\phi}(x)=-\boldsymbol{e}_{v}(x) \boldsymbol{T} \boldsymbol{R},
\end{aligned}
$$

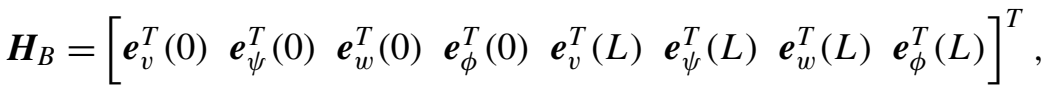

where

$$
\boldsymbol{R}=\operatorname{diag}\left[r_{j}\right], \quad \boldsymbol{T}=\operatorname{diag}\left[t_{j}\right] \quad(j=1,2, \ldots, 8) .
$$

$\boldsymbol{N}_{v}, \boldsymbol{N}_{\psi}, \boldsymbol{N}_{w}$, and $\boldsymbol{N}_{\phi}$ are the frequency-dependent dynamic shape function matrices and $\boldsymbol{d}$ is the spectral nodal DOFs vector for the transverse bending vibrations of the spinning shaft.

To formulate the spectral element equation, the weak form of (16) are obtained in the form

$$
\begin{aligned}
\int_{0}^{L}\left[E I\left(\Phi^{\prime} \delta \Phi^{\prime}+\psi^{\prime} \delta \psi^{\prime}\right)\right. & +\kappa G A\left(V^{\prime} \delta V^{\prime}+W^{\prime} \delta W^{\prime}\right)-\kappa G A\left(\psi \delta V^{\prime}+V^{\prime} \delta \psi\right) \\
& \left.+\kappa G A\left(\Phi \delta W^{\prime}+W^{\prime} \delta \Phi\right)+\kappa G A(\Phi \delta \Phi+\psi \delta \psi)\right] d x \\
& +\int_{0}^{L} i \omega \Omega \rho J(\psi \delta \Phi-\Phi \delta \psi) d x-\int_{0}^{L} \omega^{2}[\rho A(V \delta V+W \delta W)+\rho I(\Phi \delta \Phi+\psi \delta \psi)] d x \\
= & \int_{0}^{L}\left(P_{y} \delta V+T_{z} \delta \psi+P_{z} \delta W+T_{y} \delta \phi\right) d x+\left.Q_{y} \delta V\right|_{0} ^{L}+\left.M_{z} \delta \psi\right|_{0} ^{L}+\left.Q_{z} \delta W\right|_{0} ^{L}+\left.M_{y} \delta \Phi\right|_{0} ^{L} .
\end{aligned}
$$

Substituting (25) into (30) and applying the associated boundary conditions, we can get

$$
\boldsymbol{S}(\omega) \boldsymbol{d}=\boldsymbol{f}_{c}+\boldsymbol{f}_{d}
$$

where $S(\omega)$ is the spectral element matrix given by

$$
\boldsymbol{S}(\omega)=\boldsymbol{H}^{-T} \boldsymbol{D} \boldsymbol{H}^{-1}+\boldsymbol{K}_{\text {support }}+i \omega \boldsymbol{C}_{\text {support }},
$$


where

$$
\begin{array}{r}
\boldsymbol{D}(\omega)=-E I(\boldsymbol{R} \boldsymbol{K} \boldsymbol{E} \boldsymbol{K} \boldsymbol{T} \boldsymbol{R}+\boldsymbol{R} \boldsymbol{K} \boldsymbol{K} \boldsymbol{R})-\kappa G A(\boldsymbol{K} \boldsymbol{K}+\boldsymbol{T} \boldsymbol{K} \boldsymbol{K} \boldsymbol{T})+i \kappa G A(\boldsymbol{K} \boldsymbol{R}+\boldsymbol{R} \boldsymbol{K}) \\
+i \kappa G A(\boldsymbol{T} \boldsymbol{E} \boldsymbol{T} \boldsymbol{R}+\boldsymbol{R} \boldsymbol{E} \boldsymbol{K} \boldsymbol{T})+\kappa G A(\boldsymbol{R} \boldsymbol{T} \boldsymbol{T} \boldsymbol{R}+\boldsymbol{R} \boldsymbol{E} \boldsymbol{R})-\omega^{2} \rho A(\boldsymbol{E}+\boldsymbol{T} \boldsymbol{E} \boldsymbol{T}) \\
-\omega^{2} \rho I(\boldsymbol{R} \boldsymbol{T} \boldsymbol{E} \boldsymbol{R}+\boldsymbol{R} \boldsymbol{E} \boldsymbol{R})-i \omega \Omega \rho J(\boldsymbol{R} \boldsymbol{T} \boldsymbol{R}-\boldsymbol{R} \boldsymbol{E} \boldsymbol{T}) \\
\boldsymbol{K}_{\text {support }}=\left[\begin{array}{cc}
\boldsymbol{K}_{1} & \mathbf{0} \\
\mathbf{0} & \boldsymbol{K}_{2}
\end{array}\right], \quad \boldsymbol{C}_{\text {support }}=\left[\begin{array}{cc}
\boldsymbol{C}_{1} & \mathbf{0} \\
\mathbf{0} & \boldsymbol{C}_{2}
\end{array}\right],
\end{array}
$$

with the use of following definitions:

$$
\begin{aligned}
& \boldsymbol{E}(\omega)=\int_{0}^{L} \boldsymbol{e}_{v}^{T} \boldsymbol{e}_{v} d x \equiv\left[E_{l m}\right]= \begin{cases}\frac{i}{k_{l}+k_{m}}\left[e^{-i\left(k_{l}+k_{m}\right) L}-1\right] & \text { if } k_{l}+k_{m} \neq 0, \\
L & \text { if } k_{l}+k_{m}=0\end{cases} \\
& \boldsymbol{K}=\operatorname{diag}\left[k_{j}\right] \quad(j=1,2, \ldots, 8), \\
& \boldsymbol{K}_{i}=\left[\begin{array}{cccc}
K_{y y i} & 0 & \frac{1}{2}\left(K_{y z i}+K_{z y i}\right) & 0 \\
0 & 0 & 0 & 0 \\
\frac{1}{2}\left(K_{y z i}+K_{z y i}\right) & 0 & K_{z z i} & 0 \\
0 & 0 & 0 & 0
\end{array}\right] \quad(i=1,2) \\
& \boldsymbol{C}_{i}=\left[\begin{array}{cccc}
C_{y y i} & 0 & \frac{1}{2}\left(C_{y z i}+C_{z y i}\right) & 0 \\
0 & 0 & 0 & 0 \\
\frac{1}{2}\left(C_{y z i}+C_{z y i}\right) & 0 & C_{z z i} & 0 \\
0 & 0 & 0 & 0
\end{array}\right] \quad(i=1,2)
\end{aligned}
$$

In (31), $\boldsymbol{f}_{c}$ represents the spectral nodal forces and moments due to the concentrated forces and moments, while $f_{d}$ represents the ones due to the distributed forces and moments. They are defined by

$$
\begin{aligned}
& \boldsymbol{f}_{c}=\left\{\begin{array}{llllllll}
Q_{y 1} & M_{z 1} & Q_{z 1} & M_{y 1} & Q_{y 2} & M_{z 2} & Q_{z 2} & M_{y 2}
\end{array}\right\}^{T}, \\
& f_{d}=\int_{0}^{L}\left[P_{y}(x) N_{v}^{T}(x)+T_{z}(x) N_{\psi}^{T}(x)+P_{z}(x) N_{w}^{T}(x)+T_{y}(x) N_{\phi}^{T}(x)\right] d x \\
& =\left\{\begin{array}{llllllll}
F_{v 1} & F_{\psi 1} & F_{w 1} & F_{\phi 1} & F_{v 2} & F_{\psi 2} & F_{w 2} & F_{\phi 2}
\end{array}\right\}^{T} .
\end{aligned}
$$

The last term of (33) is skew symmetric and represents the gyroscopic effect.

\section{Spectral element analysis}

The spectral element (31) can be assembled in an analogous way as in conventional FEM. After imposing the relevant boundary conditions, a global dynamic stiffness matrix equation can be obtained in the form

$$
S_{g}(\omega) \boldsymbol{d}_{g}=\boldsymbol{f}_{c g}+\boldsymbol{f}_{d g}=\boldsymbol{f}_{g}
$$


where the subscripts $g$ denote the quantities for the assembled global spinning shaft system. As the spectral element matrix $\boldsymbol{S}(\omega)$ is formulated by using exact wave solutions to the frequency-domain governing differential equations, only one element will suffice for modeling a regular shaft of any length in the absence of any discontinuity or irregularity in the geometrical and material properties.

The natural frequencies $\omega_{\mathrm{NAT}}$ of a global system can be computed from the condition that the determinant of the global dynamic stiffness matrix vanishes at $\omega_{\mathrm{NAT}}$. That is

$$
\operatorname{det} \boldsymbol{S}_{g}\left(\omega_{\mathrm{NAT}}\right)=0 .
$$

To compute the roots (that is, natural frequencies $\omega_{\mathrm{NAT}}$ ) of (41), we can use a proper root-searching algorithm in conjunction with the Wittrick-William algorithm [Wittrick and Williams 1971] not to miss any roots within a frequency range specified during the root search. The spectral nodal DOFs can be exactly computed from (40) as

$$
\boldsymbol{d}_{g}=\boldsymbol{S}_{g}(\omega)^{-1}, \quad \boldsymbol{f}_{g}=\boldsymbol{T}_{g}(\omega) \boldsymbol{f}_{g},
$$

where $\boldsymbol{T}_{g}(\omega)=\boldsymbol{S}_{g}(\omega)^{-1}$ is the system transfer matrix (or frequency response function). Thus, (42) implies that the spectral nodal DOFs can be computed by convolving the system transfer matrix with the spectral nodal forces and moments. Once the spectral nodal DOFs are computed from (42), one can readily use the inverse FFT to compute the time history of the dynamic responses.

\section{Numerical examples}

5.1. Simply supported uniform shaft. Consider a simply supported uniform shaft as shown in Figure 2. The geometric and material properties of the uniform shaft are given as follows: length $2 L=2 \mathrm{~m}$, radius $r=0.02 \mathrm{~m}$, mass density $\rho=7700 \mathrm{~kg} / \mathrm{m}^{3}$, Young's modulus $E=207 \mathrm{GPa}$, shear modulus $77.6 \mathrm{GPa}$, and shear correction factor for the circular cross-section $\kappa=0.9$.

To verify the accuracy of the present spectral element model, the natural frequencies of the stationary (nonspinning) uniform shaft obtained by using the present spectral element model are compared in Table 1 with those obtained by using the finite element model (see the Appendix) as well as with those obtained by using the analytical formula given by [Blevins 1979] as

$$
f_{n}=\bar{f}_{n} \alpha_{n} \sqrt{\beta_{n}-\sqrt{\beta_{n}^{2}-\eta_{1}^{-1} \eta_{2}^{-1}}} \mathrm{~Hz},
$$

where $\bar{f}_{n}$ are the natural frequencies of the simply supported, stationary uniform Bernoulli-Euler beam and

$$
\alpha_{n}=\frac{L}{n \pi}, \quad \beta_{n}=\frac{1}{2}\left[\eta_{1}^{-1}+\left(1+\alpha_{n}^{2} \eta_{1}^{-1}\right) \eta_{2}^{-1}\right] .
$$

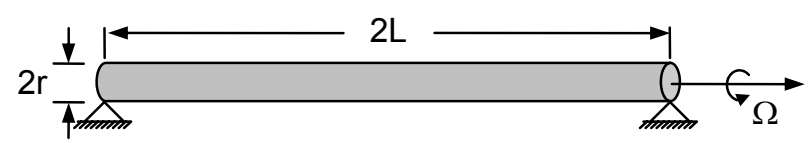

Figure 2. A simply supported uniform shaft, where $\Omega$ is the spinning speed. 


\begin{tabular}{|cccccccc|}
\hline \multicolumn{7}{c}{ FEM $(n)$} & \\
Mode & $n=2$ & $n=10$ & $n=30$ & $n=50$ & $n=100$ & SEM (1) & [Blevins 1979] \\
1st & 20.43 & 20.35 & 20.35 & 20.35 & 20.35 & 20.35 & 20.35 \\
2nd & 90.35 & 81.23 & 81.29 & 81.29 & 81.29 & 81.29 & 81.29 \\
3rd & 226.9 & 182.6 & 182.5 & 182.5 & 182.5 & 182.5 & 182.5 \\
4th & 414.1 & 324.0 & 323.3 & 323.3 & 323.3 & 323.3 & 323.3 \\
5th & - & 505.8 & 503.1 & 503.0 & 502.9 & 502.9 & 502.9 \\
10th & - & 2232 & 1952 & 1947 & 1945 & 1945 & 1945 \\
15th & - & 5521 & 4228 & 4182 & 4166 & 4160 & 4160 \\
20th & - & 10261 & 7260 & 7058 & 6982 & 6956 & 6956 \\
\hline
\end{tabular}

Table 1. Natural frequencies (in $\mathrm{Hz}$ ) of the simply supported stationary uniform shaft $(\Omega=0 \mathrm{rpm})$, with $n$ the total number of finite elements used in the analysis.

For the spectral element analysis, the whole uniform shaft is represented by using a single element, that is, a one-element model. On the other hand, for the finite element analysis, the total number of finite elements used in the analysis is increased step by step until the FEM results converge to the exact analytical results. Table 1 shows that the SEM results are indeed identical to those obtained by the analytical formula (43), while the FEM results converge to the SEM results (or the exact results) as the total number of finite elements used in the finite element analysis is increased. For instance, Table 1 shows, for the present example problem, that more than 100 finite elements must be used for the finite element analysis to satisfy an accuracy of five significant figures for the fifth and higher natural frequencies while the oneelement model suffices for the spectral element analysis. The maximum number of natural frequencies which can be obtained by finite element analysis is certainly limited by the total number of finite elements used in the analysis (for example, four natural frequencies when two finite elements are used, as shown in Table 1), while the present spectral element analysis provides an infinite number of natural frequencies.

The natural frequencies of the spinning uniform shaft are compared in Table 2. It is assumed that the uniform shaft is spinning at a constant speed of $3600 \mathrm{rpm}$. The SEM results are compared with those obtained by using the finite element model as well as with those obtained from the analytical formula given by [Zu and Han 1992] as

$$
\sin \left(\frac{L}{\sqrt{2}} \sqrt{\chi_{1} \eta_{5}+\sqrt{\chi_{1}^{2} \eta_{5}^{2}-4 \chi_{2}}}\right)=0
$$

where

$$
\begin{aligned}
& \chi_{1}=-\eta_{6} \Omega \omega+\left(\eta_{1}+\eta_{2}\right) \omega^{2}, \\
& \chi_{2}=-\omega-\eta_{3} \Omega \omega^{3}+\eta_{4} \omega^{4},
\end{aligned} \quad \eta_{4}=\frac{\rho I}{\kappa G A}, \quad \eta_{5}=\frac{\rho A}{E I}, \quad \eta_{6}=\frac{\rho J}{\rho A} .
$$

Table 2 also shows that the natural frequencies for both forward and backward whirling modes obtained by using the spectral element model (the one-element model) are very close to the results obtained by using the analytical formula (45), while those obtained by using the finite element model converge to the SEM results as the total number of finite elements used in the finite element analysis is increased. Figure 3 shows the spinning speed $\Omega$-dependence of the first and second natural frequencies, all computed 


\begin{tabular}{|c|c|c|c|c|c|c|c|c|}
\hline \multicolumn{9}{|c|}{$\operatorname{FEM}(n)$} \\
\hline \multicolumn{2}{|c|}{ Mode } & $n=2$ & $n=10$ & $n=30$ & $n=50$ & $n=100$ & SEM (1) & $\mathrm{Z} \& \mathrm{H}$ \\
\hline \multirow{2}{*}{$1 \mathrm{st}$} & forward & 20.45 & 20.37 & 20.37 & 20.37 & 20.37 & 20.37 & 20.37 \\
\hline & backward & 20.42 & 20.34 & 20.34 & 20.34 & 20.34 & 20.34 & \\
\hline \multirow{2}{*}{ 2nd } & forward & 90.41 & 81.36 & 81.34 & 81.34 & 81.34 & 81.34 & 81.34 \\
\hline & backward & 90.29 & 81.24 & 81.23 & 81.23 & 81.23 & 81.23 & \\
\hline \multirow{2}{*}{$3 \mathrm{rd}$} & forward & 227.1 & 182.7 & 182.6 & 182.6 & 182.6 & 182.6 & 182.6 \\
\hline & backward & 226.8 & 182.5 & 182.3 & 182.3 & 182.3 & 182.3 & \\
\hline \multirow{2}{*}{4 th } & forward & 414.4 & 324.3 & 323.5 & 323.5 & 323.5 & 323.5 & 323.5 \\
\hline & backward & 413.9 & 323.8 & 323.1 & 323.0 & 323.0 & 323.0 & \\
\hline \multirow{2}{*}{5 th } & forward & - & 506.1 & 503.4 & 503.3 & 503.3 & 503.3 & 503.3 \\
\hline & backward & - & 505.4 & 502.7 & 502.6 & 502.6 & 502.6 & \\
\hline \multirow{2}{*}{ 10th } & forward & - & 2234 & 1953 & 1948 & 1947 & 1946 & 1946 \\
\hline & backward & - & 2231 & 1951 & 1946 & 1944 & 1943 & \\
\hline \multirow{2}{*}{15 th } & forward & - & 5524 & 4231 & 4185 & 4168 & 4163 & 4163 \\
\hline & backward & - & 5518 & 4225 & 4180 & 4163 & 4158 & \\
\hline \multirow{2}{*}{20 th } & forward & - & 10267 & 7264 & 7061 & 6985 & 6961 & 6961 \\
\hline & backward & - & 10255 & 7257 & 7054 & 6978 & 6954 & \\
\hline
\end{tabular}

Table 2. Natural frequencies (in $\mathrm{Hz}$ ) of the simply supported spinning uniform shaft $(\Omega=3600 \mathrm{rpm}$ ), with $n$ the total number of finite elements used in the analysis, and where $\mathrm{Z} \& \mathrm{H}$ indicates data from [Zu and Han 1992].

by using the present spectral element model. Figure 3 shows that both forward and backward whirling modes appear when the uniform shaft starts spinning.

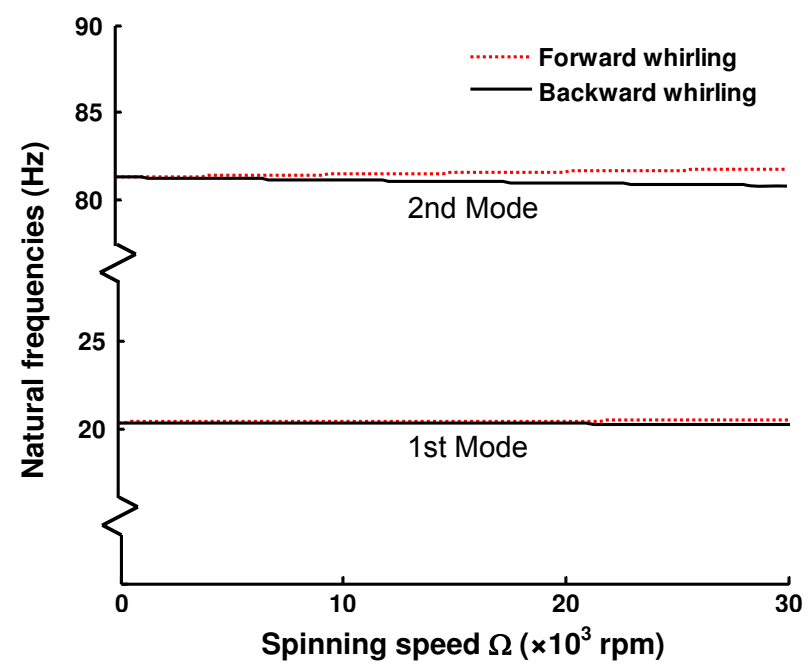

Figure 3. Natural frequencies versus spinning speed $\Omega$ of the simply supported uniform shaft. 


\begin{tabular}{|c|c|c|c|c|c|c|c|c|}
\hline \multicolumn{9}{|c|}{$\operatorname{FEM}(n)$} \\
\hline \multicolumn{2}{|c|}{ Mode } & $n=2$ & $n=10$ & $n=30$ & $n=50$ & $n=100$ & SEM (1) & $\mathrm{E} \& \mathrm{E}$ \\
\hline \multirow{2}{*}{$1 \mathrm{st}$} & forward & 20.44 & 20.36 & 20.36 & 20.36 & 20.36 & 20.36 & 20.36 \\
\hline & backward & 20.43 & 20.35 & 20.35 & 20.35 & 20.35 & 20.35 & 20.35 \\
\hline \multirow{2}{*}{ 2nd } & forward & 90.44 & 81.38 & 81.37 & 81.36 & 81.36 & 81.36 & 81.36 \\
\hline & backward & 90.26 & 81.22 & 81.21 & 81.21 & 81.21 & 81.21 & 81.21 \\
\hline \multirow{2}{*}{$3 r d$} & forward & 227.5 & 183.0 & 182.9 & 182.8 & 182.8 & 182.8 & 182.8 \\
\hline & backward & 226.4 & 182.2 & 182.1 & 182.0 & 182.0 & 182.0 & 182.0 \\
\hline \multirow{2}{*}{ 4th } & forward & 415.9 & 325.3 & 324.6 & 324.5 & 324.5 & 324.5 & 324.5 \\
\hline & backward & 412.4 & 322.8 & 322.1 & 322.0 & 322.0 & 322.0 & 322.0 \\
\hline \multirow{2}{*}{5 th } & forward & - & 508.8 & 506.1 & 506.0 & 506.0 & 506.0 & 506.0 \\
\hline & backward & - & 502.8 & 500.1 & 500.0 & 500.0 & 500.0 & 499.9 \\
\hline \multirow{2}{*}{ 10th } & forward & - & 2289 & 2001 & 1995 & 1994 & 1989 & 1989 \\
\hline & backward & - & 2180 & 1912 & 1907 & 1906 & 1901 & 1901 \\
\hline \multirow{2}{*}{15 th } & forward & - & 5835 & 4413 & 4360 & 4341 & 4350 & 4350 \\
\hline & backward & - & 5252 & 4063 & 4022 & 4007 & 3971 & 3971 \\
\hline \multirow{2}{*}{ 20th } & forward & - & 11449 & 7770 & 7548 & 7465 & 7454 & 7454 \\
\hline & backward & - & 10971 & 6752 & 6563 & 6489 & 6462 & 6462 \\
\hline
\end{tabular}

Table 3. Critical speeds (in $\mathrm{Hz}$ ) of the simply supported spinning uniform shaft, with $n$ the total number of finite elements used in the analysis, and where E\&E indicates data from [Eshleman and Eubanks 1969].

The critical speeds of the uniform shaft are compared in Table 3. The critical speeds of a spinning shaft are defined by the spinning speeds which are identical to the natural frequencies of the shaft. As the gyroscopic effect will change the effective compliance of the shaft to raise or lower the natural frequencies, one critical speed is raised (forward whirling mode) while one is lowered (backward whirling mode). The critical speeds obtained by using the present spectral element model are compared with the results obtained by using the finite element model and the analytical formula given by [Eshleman and Eubanks 1969] as

$$
\Omega_{n}= \begin{cases}\bar{f}_{n} \sqrt{\frac{\alpha_{n}^{2}}{\alpha_{n}^{2}+\eta_{2}-\eta_{1}}}(\mathrm{~Hz}) & \text { (forward whirling), } \\ \bar{f}_{n} \sqrt{\frac{\alpha_{n}^{2}}{\alpha_{n}^{2}+\eta_{2}+3 \eta_{1}}}(\mathrm{~Hz}) & \text { (backward whirling) }\end{cases}
$$

It is also obvious from Table 3 that the critical speeds of the present spectral element model (the oneelement model) are very close to the results of the analytical formula (47), while the FEM results certainly converge to the SEM results as the total number of finite elements used in the finite element analysis is increased. 

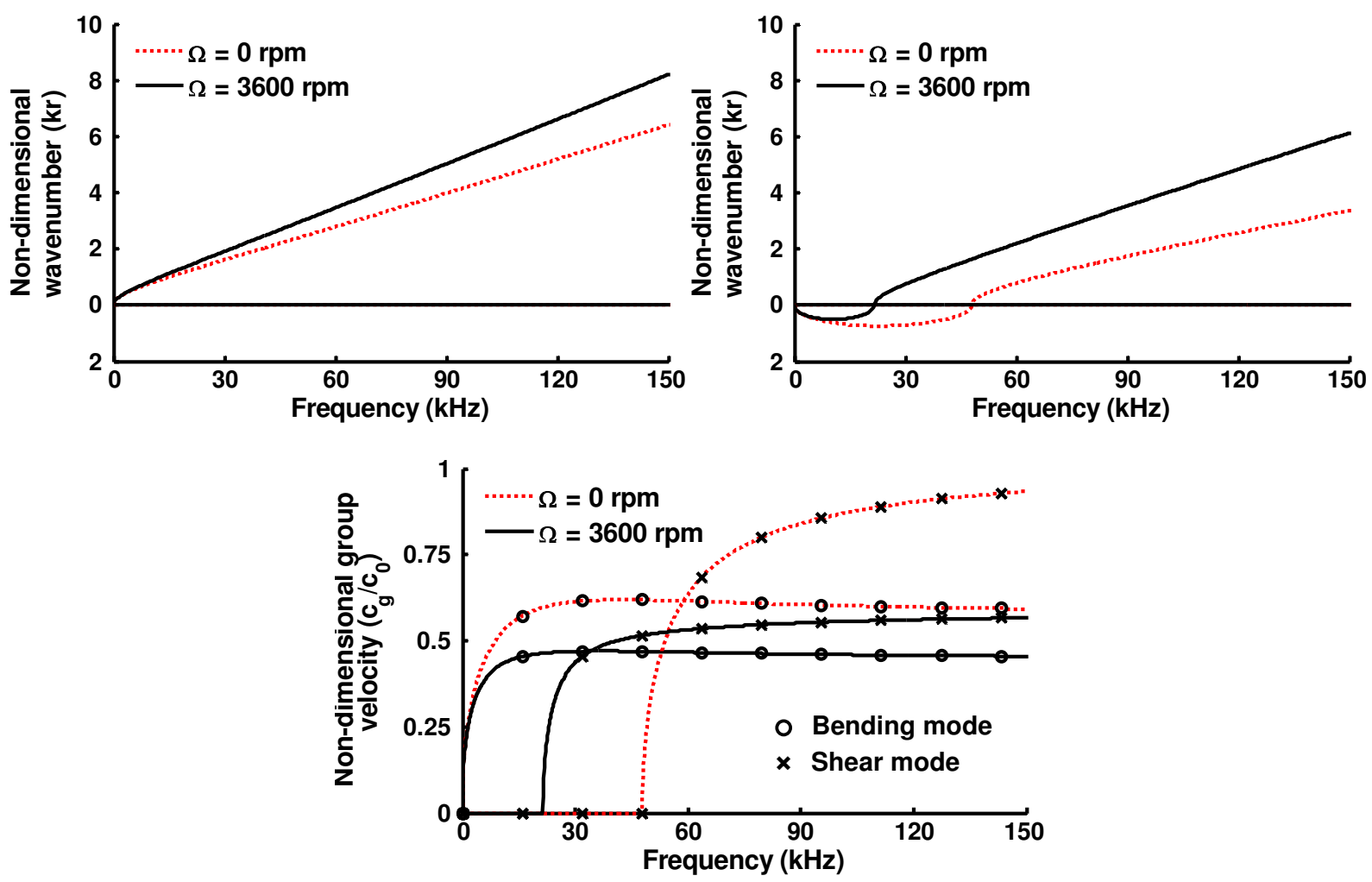

Figure 4. Dispersion curves of the simply supported uniform shaft.

In summary, the results displayed in Tables 1,2, and 3 confirm the accuracy of the present spectral element model when compared with the conventional finite element model which is provided in the Appendix.

Lastly, Figure 4 compares the dispersion curves when the shaft is stationary and rotating at a constant speed of $3600 \mathrm{rpm}$. In the last graph, the group velocities are nondimensionalized with respect to $c_{0}=$ $\sqrt{E I / \rho A}$. Figure 4 shows that the group velocity of the bending (flexural) wave mode decreases as the shaft rotates. For the shear wave mode, the cutoff frequency shifts to a lower frequency as the shaft rotates and its group velocity also decreases at higher frequencies than the cutoff frequency.

5.2. Bearing-supported uniform shaft. To investigate the effect of the stiffness and damping of the bearing-supports on the natural and critical speeds of a spinning shaft, we consider a bearing-supported uniform shaft as shown in Figure 5 as the second example problem. The geometric and material properties for the bearing-supported uniform shaft are exactly same as those for the previous simply supported

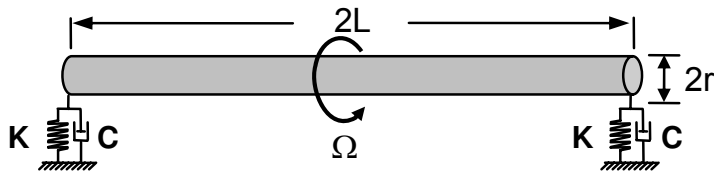

Figure 5. A bearing-supported uniform shaft, where $\Omega$ is the spinning speed. 
uniform shaft. It is assumed that the stiffness and damping properties of the left bearing-support are identical to those of the right. For the stiffness and damping properties of the bearing-supports, we consider three cases:

- Case A: $K_{y y}=K_{z z}=1.0 \times 10^{6} \mathrm{~N} / \mathrm{m}, K_{y z}=K_{z y}=0 \mathrm{~N} / \mathrm{m}, C_{y y}=C_{z z}=400 \mathrm{Ns} / \mathrm{m}$, and $C_{y z}=$ $C_{z y}=0 \mathrm{Ns} / \mathrm{m}$;

- Case B: $K_{y y}=K_{z z}=1.0 \times 10^{8} \mathrm{~N} / \mathrm{m}, K_{y z}=K_{z y}=0 \mathrm{~N} / \mathrm{m}, C_{y y}=C_{z z}=400 \mathrm{Ns} / \mathrm{m}$, and $C_{y z}=$ $C_{z y}=0 \mathrm{Ns} / \mathrm{m}$;

- Case C: $K_{y y}=K_{z z}=1.0 \times 10^{6} \mathrm{~N} / \mathrm{m}, K_{y z}=K_{z y}=0 \mathrm{~N} / \mathrm{m}, C_{y y}=C_{z z}=800 \mathrm{Ns} / \mathrm{m}$, and $C_{y z}=$ $C_{z y}=0 \mathrm{Ns} / \mathrm{m}$.

Compared to Case A, Case B has higher stiffness, while Case C has lower damping.

For these three cases of bearing-supported uniform shaft problems, exact solutions are not available from the literature. Thus, as shown in Tables 4, 5, and 6, the FEM results are also provided as reference solutions to evaluate the present SEM results. The one-element model suffices for accurate SEM results. On the other hand, a sufficient number of finite elements (100 finite elements) are used to obtain sufficiently converged accurate FEM results.

Table 4 shows the lowest three natural frequencies for uniform shafts which are not spinning, while Table 5 shows the forward and backward natural frequencies of the lowest three modes for uniform shafts which are spinning at $\Omega=3600 \mathrm{rpm}$. Lastly Table 6 shows the forward and backward critical speeds of

\begin{tabular}{|lcccccc|}
\hline & \multicolumn{2}{c}{ Case A } & \multicolumn{2}{c}{ Case B } & \multicolumn{2}{c|}{ Case C } \\
Mode & SEM (1) & FEM (100) & SEM (1) & FEM (100) & SEM (1) & FEM (100) \\
1st & 19.13 & 19.13 & 20.34 & 20.34 & 19.14 & 19.14 \\
2nd & 63.61 & 63.61 & 81.08 & 81.08 & 64.19 & 64.19 \\
3rd & 110.6 & 110.6 & 181.4 & 181.4 & 111.5 & 111.5 \\
\hline
\end{tabular}

Table 4. Natural frequencies (in $\mathrm{Hz}$ ) of the simply supported stationary stepped shafts $(\Omega=0 \mathrm{rpm})$, with the number in parentheses being the total number of finite elements used in the analysis.

\begin{tabular}{|c|c|c|c|c|c|c|c|}
\hline \multirow{2}{*}{\multicolumn{2}{|c|}{ Mode }} & \multicolumn{2}{|c|}{ Case A } & \multicolumn{2}{|c|}{ Case B } & \multicolumn{2}{|c|}{ Case C } \\
\hline & & SEM (1) & FEM (100) & SEM (1) & FEM (100) & SEM (1) & FEM (100) \\
\hline & forward & 19.14 & 19.14 & 20.35 & 20.35 & 19.15 & 19.15 \\
\hline & backward & 19.12 & 19.12 & 20.32 & 20.32 & 19.13 & 19.13 \\
\hline \multirow{2}{*}{ 2nd } & forward & 63.64 & 63.64 & 81.14 & 81.14 & 64.22 & 64.22 \\
\hline & backward & 63.59 & 63.59 & 81.02 & 81.02 & 64.17 & 64.17 \\
\hline & forward & 110.7 & 110.7 & 181.5 & 181.5 & 111.6 & 111.6 \\
\hline & backward & 110.6 & 110.6 & 181.3 & 181.3 & 111.5 & 111.5 \\
\hline
\end{tabular}

Table 5. Natural frequencies (in $\mathrm{Hz}$ ) of the simply supported spinning stepped shafts ( $\Omega=3600 \mathrm{rpm}$ ), with the number in parentheses being the total number of finite elements used in the analysis. 


\begin{tabular}{|c|c|c|c|c|c|c|c|}
\hline \multirow{2}{*}{\multicolumn{2}{|c|}{ Mode }} & \multicolumn{2}{|c|}{ Case A } & \multicolumn{2}{|c|}{ Case B } & \multicolumn{2}{|c|}{ Case C } \\
\hline & & SEM (1) & FEM (100) & SEM (1) & FEM (100) & SEM (1) & FEM (100) \\
\hline \multirow{2}{*}{$1 \mathrm{st}$} & forward & 19.14 & 19.14 & 20.34 & 20.34 & 19.143 & 19.143 \\
\hline & backward & 19.13 & 19.13 & 20.33 & 20.33 & 19.136 & 19.136 \\
\hline \multirow{2}{*}{ 2nd } & forward & 63.64 & 63.64 & 81.16 & 81.16 & 64.22 & 64.22 \\
\hline & backward & 63.59 & 63.59 & 81.00 & 81.00 & 64.17 & 64.17 \\
\hline \multirow{2}{*}{ 3rd } & forward & 110.7 & 110.7 & 181.8 & 181.8 & 111.6 & 111.6 \\
\hline & backward & 110.5 & 110.5 & 181.0 & 181.0 & 111.4 & 111.4 \\
\hline
\end{tabular}

Table 6. Critical speeds (in $\mathrm{Hz}$ ) of the simply supported spinning stepped shafts, with the number in parentheses being the total number of finite elements used in the analysis.

the lowest three modes. The effects of the stiffness and damping of the bearing-supports on the natural frequencies and critical speeds can be observed in Tables 4, 5, and 6. When compared with Case A, both Cases $\mathrm{B}$, with bearing-supports of higher stiffness, and $\mathrm{C}$, with bearing-supports of higher damping, have higher natural frequencies and critical speeds.

5.3. Bearing-supported stepped shaft. As the third example problem, consider a bearing-supported stepped shaft which consists of two uniform shafts of equal length $L=1 \mathrm{~m}$ as shown in Figure 6 . The material properties for the two uniform shafts are identical to those used the previous two example problems. The spring constants and viscous damping coefficients for the left and right bearing-supports are identical, and they are assumed to be identical to those for Case A of the previous bearing-supported uniform shaft problem. For the radii of the two equal-length uniform shafts, we consider three cases:

- Case I: $r_{1}=r_{2}=0.02 \mathrm{~m}$;

- Case II: $r_{1}=0.02 \mathrm{~m}, r_{2}=0.01 \mathrm{~m}$;

- Case III: $r_{1}=0.02 \mathrm{~m}, r_{2}=0.03 \mathrm{~m}$.

Exact solutions are not available from the literature for these three cases of bearing-supported stepped shaft problems. Thus, as shown in Tables 7, 8, and 9, the FEM results are also provided as the reference solutions to evaluate the present SEM results. A sufficient number of finite elements (100 finite elements) is used to obtain sufficiently converged accurate FEM results. For the SEM results, a one-element model is used for Case I, while two-element models are used for Cases II and III due to the existence of a single geometric discontinuity at the middle of the stepped shafts.

Table 7 displays the lowest three natural frequencies when the stepped shafts are not spinning, while Table 8 displays the forward and backward natural frequencies of the lowest three modes when the stepped shafts are spinning at $\Omega=3600 \mathrm{rpm}$. Lastly Table 9 displays the forward and backward critical

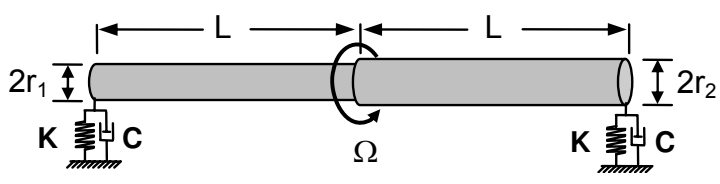

Figure 6. A bearing-supported stepped shaft, where $\Omega$ is the spinning speed. 
speeds of the lowest three modes. The natural frequencies and critical speeds for Case III are shown to be higher than for Cases I and II for the first mode. However, for the second and third modes, the values for Case I are higher than for Cases II and III. In addition, the natural frequencies and critical speeds given in Tables 7, 8, and 9 for the bearing-supported uniform shaft (Case I) are shown to be lower than the values given in Tables 1, 2, and 3 for the simply supported uniform shaft.

Figure 7 shows the first three normalized modes of the transverse displacement $v(x, t)$ when the stepped shafts are spinning at $\Omega=0 \mathrm{rpm}$ and $\Omega=3600 \mathrm{rpm}$. The mode shapes for the stepped shafts

\begin{tabular}{|lcccccc|}
\hline & \multicolumn{2}{c}{ Case I } & \multicolumn{2}{c}{ Case II } & \multicolumn{2}{c|}{ Case III } \\
Mode & SEM (1) & FEM (100) & SEM (2) & FEM (100) & SEM (2) & FEM (100) \\
1st & 19.13 & 19.13 & 9.563 & 9.563 & 19.28 & 19.28 \\
2nd & 63.61 & 63.61 & 56.32 & 56.32 & 58.46 & 58.46 \\
3rd & 110.6 & 110.6 & 93.15 & 93.15 & 103.2 & 103.2 \\
\hline
\end{tabular}

Table 7. Natural frequencies (in $\mathrm{Hz}$ ) of the bearing-supported stationary stepped shafts $(\Omega=0 \mathrm{rpm}$ ), with the number in parentheses being the total number of finite elements used in the analysis.

\begin{tabular}{|c|c|c|c|c|c|c|c|}
\hline \multirow{2}{*}{\multicolumn{2}{|c|}{ Mode }} & \multicolumn{2}{|c|}{ Case I } & \multicolumn{2}{|c|}{ Case II } & \multicolumn{2}{|c|}{ Case III } \\
\hline & & SEM (1) & FEM (100) & SEM (2) & FEM (100) & SEM (2) & FEM (100) \\
\hline & forward & 19.14 & 19.14 & 9.578 & 9.578 & 19.29 & 19.29 \\
\hline & backward & 19.12 & 19.12 & 9.551 & 9.551 & 19.26 & 19.26 \\
\hline \multirow{2}{*}{ 2nd } & forward & 63.64 & 63.64 & 56.34 & 56.34 & 58.51 & 58.51 \\
\hline & backward & 63.59 & 63.59 & 56.30 & 56.30 & 58.42 & 58.42 \\
\hline \multirow{2}{*}{$3 \mathrm{rd}$} & forward & 110.7 & 110.7 & 93.20 & 93.20 & 103.3 & 103.3 \\
\hline & backward & 110.6 & 110.6 & 93.10 & 93.10 & 103.1 & 103.1 \\
\hline
\end{tabular}

Table 8. Natural frequencies (in $\mathrm{Hz}$ ) of the bearing-supported spinning stepped shafts $(\Omega=3600 \mathrm{rpm}$ ), with the number in parentheses being the total number of finite elements used in the analysis.

\begin{tabular}{|c|c|c|c|c|c|c|c|}
\hline \multirow{2}{*}{\multicolumn{2}{|c|}{ Mode }} & \multicolumn{2}{|c|}{ Case I } & \multicolumn{2}{|c|}{ Case II } & \multicolumn{2}{|c|}{ Case III } \\
\hline & & SEM (1) & FEM (100) & SEM (2) & FEM (100) & SEM (2) & FEM (100) \\
\hline & forward & 19.14 & 19.14 & 9.565 & 9.565 & 19.28 & 19.28 \\
\hline & backward & 19.13 & 19.13 & 9.561 & 9.561 & 19.27 & 19.27 \\
\hline & forward & 63.64 & 63.64 & 56.34 & 56.34 & 58.51 & 58.51 \\
\hline & backward & 63.59 & 63.59 & 56.30 & 56.30 & 58.42 & 58.42 \\
\hline & forward & 110.7 & 110.7 & 93.23 & 93.23 & 103.4 & 103.4 \\
\hline & backward & 110.5 & 110.5 & 93.07 & 93.07 & 103.1 & 103.1 \\
\hline
\end{tabular}

Table 9. Critical speeds (in $\mathrm{Hz}$ ) of the bearing-supported spinning stepped shafts, with the number in parentheses being the total number of finite elements used in the analysis. 

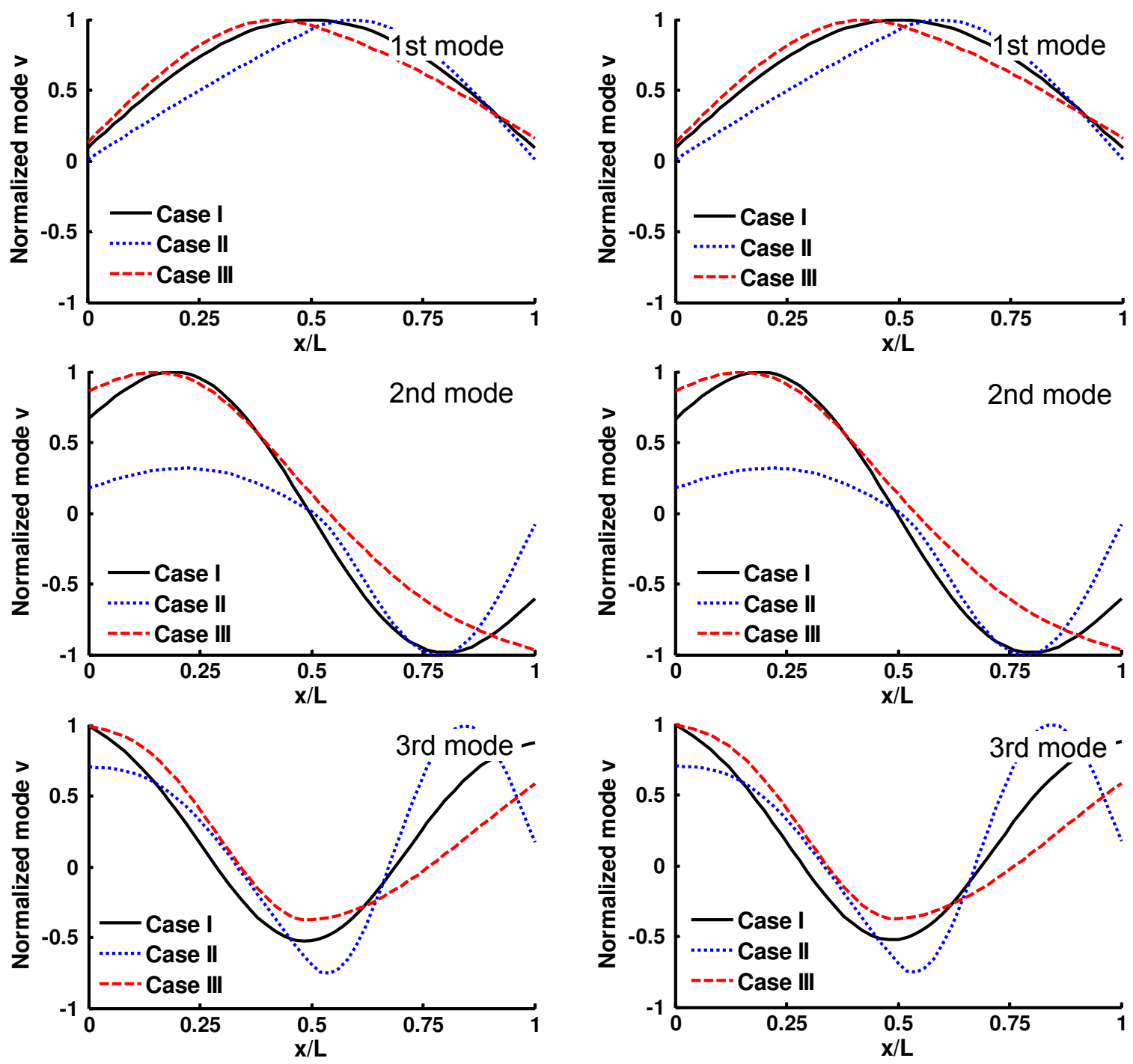

(a) $\Omega=0 \mathrm{rpm}$

(b) $\Omega=3600 \mathrm{rpm}$

Figure 7. The first three normalized modes of the bearing-supported stepped shafts.

(Cases II and III) are shown to deviate significantly from those for the uniform shaft (Case I) at both $\Omega=0 \mathrm{rpm}$ and $\Omega=3600 \mathrm{rpm}$. Though the mode shapes are dependent on the spinning speed, Figure 7 shows that the change of mode shapes at $\Omega=3600 \mathrm{rpm}$ is not so significant for the example shafts considered herein.

\section{Conclusions}

This paper develops a spectral element model for a spinning uniform shaft. The spinning uniform shaft is represented by a spinning uniform Timoshenko beam model and its bearing-supports are represented 
by two translational springs and two rotational springs. The spectral element model is then used to investigate the natural frequencies and critical speeds of the simply supported and bearing-supported spinning uniform shafts and the results are compared with the results obtained by using the conventional finite element model and the analytical theories available in existing references. It is numerically shown that the present spectral element model provides extremely accurate results by using only a small number of finite elements when compared with the conventional finite element model. In addition, some numerical investigation is also conducted for the bearing-supported stepped shafts.

\section{Appendix: Finite element model}

The equations of motion for the transverse bending vibration are given by (10) and the corresponding weak form can be derived in the form

$$
\begin{aligned}
& \int_{0}^{L}\left[E I\left(\phi^{\prime} \delta \phi^{\prime}+\psi^{\prime} \delta \psi^{\prime}\right)+\kappa G A\left(v^{\prime} \delta v^{\prime}+w^{\prime} \delta w^{\prime}\right)-\kappa G A\left(\psi \delta v^{\prime}+v^{\prime} \delta \psi\right)+\kappa G A\left(\phi \delta w^{\prime}+w^{\prime} \delta \phi\right)\right. \\
& +\kappa G A(\phi \delta \phi+\psi \delta \psi)] d x+\int_{0}^{L} \Omega \rho J(\dot{\psi} \delta \phi-\dot{\phi} \delta \psi) d x+\int_{0}^{L}[\rho A(\ddot{v} \delta v+\ddot{w} \delta w)+\rho I(\ddot{\phi} \delta \phi+\ddot{\psi} \delta \psi)] d x \\
& \left.\quad=\int_{0}^{L}\left(p_{y} \delta v+\tau_{z} \delta \psi+p_{z} \delta w+\tau_{y} \delta \phi\right) d x+\left.Q_{y} \delta v\right|_{0} ^{L}+\left.M_{z} \delta \psi\right|_{0} ^{L}+\left.Q_{z} \delta w\right|_{0} ^{L}+\left.M_{y} \delta \phi\right|_{0} ^{L} . \quad \text { (A. } 1\right)
\end{aligned}
$$

The displacement fields $v(x, t), w(x, t), \phi(x, t)$, and $\psi(x, t)$ are represented by

$$
v=N_{v}(x) d(t), \quad w=N_{w}(x) d(t), \quad \phi=N_{\phi}(x) d(t), \quad \psi=N_{\psi}(x) d(t),
$$

where

$$
\boldsymbol{d}(t)=\left\{\begin{array}{ll}
\boldsymbol{d}_{1}(t) \boldsymbol{d}_{2}(t)
\end{array}\right\}^{T}, \quad \boldsymbol{d}_{j}(t)=\left\{\begin{array}{llll}
v_{j}(t) & \psi_{j}(t) & w_{j}(t) & \phi_{j}(t)
\end{array}\right\}^{T} \quad(j=1,2),
$$

and

$$
\begin{aligned}
& \boldsymbol{N}_{v}(x)=\left[(1-\xi)\left(2-\xi-\xi^{2}+6 r\right)(R / 4) \quad L\left(1-\xi^{2}\right)(1-\xi+3 r)(R / 8) 00\right. \\
& \left.(1+\xi)\left(2+\xi-\xi^{2}+6 r\right)(R / 4)-L\left(1-\xi^{2}\right)(1+\xi+3 r)(R / 8) \quad 0 \quad 0\right], \\
& N_{w}(x)=\left[\begin{array}{lll}
0 & 0 & (1-\xi)\left(2-\xi-\xi^{2}+6 r\right)(R / 4)-L\left(1-\xi^{2}\right)(1-\xi+3 r)(R / 8)
\end{array}\right. \\
& \left.00(1+\xi)\left(2+\xi-\xi^{2}+6 r\right)(R / 4) L\left(1-\xi^{2}\right)(1+\xi+3 r)(R / 8)\right], \\
& N_{\phi}(x)=\left[\begin{array}{lll}
0 & 0 & 3\left(1-\xi^{2}\right)(R / 2 L)-(1-\xi)(1+3 \xi-6 r)(R / 4)
\end{array}\right. \\
& \left.00-3\left(1-\xi^{2}\right)(R / 2 L)-(1+\xi)(1-3 \xi-6 r)(R / 4)\right], \\
& N_{\psi}(x)=\left[-3\left(1-\xi^{2}\right)(R / 2 L)-(1-\xi)(1+3 \xi-6 r)(R / 4) \quad 0 \quad 0\right. \\
& \left.3\left(1-\xi^{2}\right)(R / 2 L)-(1+\xi)(1-3 \xi-6 r)(R / 4) \quad 0 \quad 0\right],
\end{aligned}
$$

with

$$
\xi=2\left(\frac{x}{L}\right)-1 \quad(0 \leq x \leq L), \quad r=\frac{4 E I}{\kappa G A L^{2}}, \quad R=\frac{1}{1+3 r} .
$$


Substitution of (A.2) into (A.1) gives the finite element equation in the form

$$
\boldsymbol{M} \ddot{\boldsymbol{d}}(t)+\boldsymbol{G} \dot{\boldsymbol{d}}(t)+\boldsymbol{K} \boldsymbol{d}(t)=\boldsymbol{f}(t)
$$

where

$$
\begin{aligned}
& \boldsymbol{M}=\left[m_{i j}\right]=\int_{0}^{L}\left[\rho A\left(\boldsymbol{N}_{v}^{T} \boldsymbol{N}_{v}+\boldsymbol{N}_{w}^{T} \boldsymbol{N}_{w}\right)+\rho I\left(\boldsymbol{N}_{\phi}^{T} \boldsymbol{N}_{\phi}+\boldsymbol{N}_{\psi}^{T} \boldsymbol{N}_{\psi}\right)\right] d x, \\
& \boldsymbol{G}=\left[g_{i j}\right]= \int_{0}^{L} \Omega \rho J\left(\boldsymbol{N}_{\phi}^{T} \boldsymbol{N}_{\psi}-\boldsymbol{N}_{\psi}^{T} \boldsymbol{N}_{\phi}\right) d x, \\
& \boldsymbol{K}=\left[k_{i j}\right]=\int_{0}^{L}\left[E I\left(\boldsymbol{N}_{\phi}^{\prime T} \boldsymbol{N}_{\phi}^{\prime}+\boldsymbol{N}_{\psi}^{\prime T} \boldsymbol{N}_{\psi}^{\prime}\right)+\kappa G A\left(\boldsymbol{N}_{v}^{\prime T} \boldsymbol{N}_{v}^{\prime}+\boldsymbol{N}_{w}^{\prime T} \boldsymbol{N}_{w}^{\prime}+\boldsymbol{N}_{\phi}^{T} \boldsymbol{N}_{\phi}\right.\right. \\
&\left.\left.\quad+\boldsymbol{N}_{\psi}^{T} \boldsymbol{N}_{\psi}+\boldsymbol{N}_{w}^{\prime T} \boldsymbol{N}_{\phi}+\boldsymbol{N}_{\phi}^{T} \boldsymbol{N}_{w}^{\prime}-\boldsymbol{N}_{v}^{\prime T} \boldsymbol{N}_{\psi}-\boldsymbol{N}_{\psi}^{T} \boldsymbol{N}_{v}^{\prime}\right)\right] d x,
\end{aligned}
$$

and

$$
\begin{aligned}
& \boldsymbol{f}(t)=\boldsymbol{f}_{c}(t)+\boldsymbol{f}_{d}(t) \equiv\left\{\boldsymbol{f}_{1}(t) \boldsymbol{f}_{2}(t)\right\}^{T},
\end{aligned}
$$

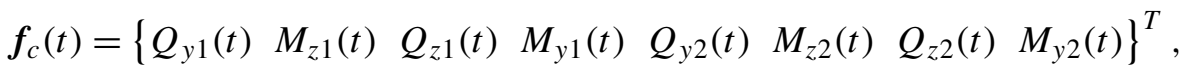

$$
\begin{aligned}
& \boldsymbol{f}_{d}(t)=\int_{0}^{L}\left(\boldsymbol{N}_{v}^{T} p_{y}+\boldsymbol{N}_{w}^{T} p_{z}+\boldsymbol{N}_{\phi}^{T} \tau_{y}+\boldsymbol{N}_{\psi}^{T} \tau_{z}\right) d x, \\
& f_{i}(t)=\left\{\begin{array}{llll}
f_{v i}(t) & f_{\psi i}(t) & f_{w i}(t) & f_{\phi i}(t)
\end{array}\right\}^{T} \quad(i=1,2) .
\end{aligned}
$$

$\boldsymbol{M}$ and $\boldsymbol{K}$ are the $8 \times 8$ symmetric matrices and $\boldsymbol{G}$ is the $8 \times 8$ skew symmetric matrix. Their components are given by

$$
\begin{aligned}
& m_{11}=m_{33}=m_{55}=m_{77}=12 \alpha_{1}\left(26+147 r+210 r^{2}\right)+36 \alpha_{2}, \\
& m_{12}=-m_{34}=-m_{56}=m_{78}=\alpha_{1} L\left(44+231 r+315 r^{2}\right)+3 \alpha_{2} L(1-15 r), \\
& m_{15}=m_{37}=36 \alpha_{1}\left(3+21 r+35 r^{2}\right)-36 \alpha_{2}, \\
& m_{16}=-m_{25}=-m_{38}=m_{47}=-\alpha_{1} L\left(26+189 r+315 r^{2}\right)+3 \alpha_{2} L(1-15 r), \\
& m_{22}=m_{44}=m_{66}=m_{88}=\alpha_{1} L^{2}\left(8+42 r+63 r^{2}\right)+\alpha_{2} L^{2}\left(4+15 r+90 r^{2}\right), \\
& m_{26}=m_{48}=-3 \alpha_{1} L^{2}\left(2+14 r+21 r^{2}\right)-\alpha_{2} L^{2}\left(1+15 r-45 r^{2}\right),
\end{aligned}
$$

and other $m_{i j}=0$,

$$
\begin{aligned}
& g_{13}=-g_{17}=g_{35}=g_{57}=36 \eta, \\
& g_{14}=g_{18}=-g_{23}=g_{27}=g_{36}=g_{45}=-g_{58}=g_{67}=-3 \eta L(1-15 r), \\
& g_{24}=g_{68}=-\eta L^{2}\left(4+15 r+90 r^{2}\right), \\
& g_{28}=-g_{46}=\eta L^{2}\left(1+15 r-45 r^{2}\right),
\end{aligned}
$$


and other $g_{i j}=0$, and

$$
\begin{aligned}
& k_{11}=-k_{15}=k_{33}=-k_{37}=k_{55}=k_{77}=12 \beta_{1}+540 \beta_{2} r^{2}, \\
& k_{12}=-k_{25}=-k_{34}=k_{47}=6 \beta_{1} L+270 \beta_{2} L r^{2}, \\
& k_{16}=-k_{38}=-k_{56}=k_{78}=6 \beta_{1} L+90 \beta_{2} L r(1+3 r), \\
& k_{22}=k_{44}=\beta_{1} L^{2}\left(4+6 r+9 r^{2}\right)+135 \beta_{2} L^{2} r^{2}, \\
& k_{26}=k_{48}=\beta_{1} L^{2}\left(2-6 r-9 r^{2}\right)+45 \beta_{2} L^{2} r(1+3 r), \\
& k_{66}=k_{88}=\beta_{1} L^{2}\left(4+6 r+9 r^{2}\right)+\beta_{2} L^{2}\left(47+210 r+315 r^{2}\right),
\end{aligned}
$$

and other $k_{i j}=0$, where

$$
\begin{aligned}
& \alpha_{1}=\frac{R^{2}}{840} \rho A L, \quad \beta_{1}=\frac{R^{2}}{L^{3}} E I, \\
& \alpha_{2}=\frac{R^{2}}{30 L} \rho I, \quad \beta_{2}=\frac{R^{2}}{60 L} \kappa G A, \\
& \eta=\frac{R^{2}}{30 L} \rho J \Omega .
\end{aligned}
$$

\section{References}

[Blevins 1979] R. D. Blevins, Formulas for natural frequency and mode shape, Van Nostrand Reinhold, New York, 1979.

[Chen 2010] W.-R. Chen, "On the vibration and stability of spinning axially loaded pre-twisted Timoshenko beams", Finite Elem. Anal. Des. 46:11 (2010), 1037-1047.

[Doyle 1997] J. F. Doyle, Wave propagation in structures: spectral analysis using fast discrete Fourier transforms, Springer, New York, 1997.

[Ehrich 1992] F. F. Ehrich, Handbook of rotordynamics, McGraw-Hill, New York, 1992.

[Eshleman and Eubanks 1969] R. L. Eshleman and R. A. Eubanks, "On the critical speeds of a continuous rotor", J. Eng. Ind. (ASME) 91 (1969), 1180-1188.

[Ghoneim and Lawrie 2007] H. Ghoneim and D. J. Lawrie, "Dynamic analysis of a hyperbolic composite coupling", J. Sound Vib. 301:1-2 (2007), 43-58.

[Kane and Torby 1991] K. Kane and B. J. Torby, "The extended modal reduction method applied to rotor dynamic problems", J. Vib. Acoust. (ASME) 113:1 (1991), 79-84.

[Lee 2009] U. Lee, Spectral element method in structural dynamics, Wiley, Singapore, 2009.

[Lee et al. 2000] U. Lee, J. Kim, and A. Y. T. Leung, "The spectral element method in structural dynamics", Shock Vib. Digest 32:6 (2000), 451-465.

[Lund 1974] J. W. Lund, "Stability and damped critical speeds of a flexible rotor in fluid-film bearings", J. Eng. Ind. (ASME) 96:2 (1974), 509-517.

[Meirovitch 1980] L. Meirovitch, Computational methods in structural dynamics, Monographs and Textbooks on Mechanics of Solids and Fluids: Mechanics of Dynamical Systems 5, Sijthoff \& Noordhoff, Alphen aan den Rijn, 1980.

[Nelson 1980] H. D. Nelson, "A finite rotating shaft element using Timoshenko beam theory”, J. Mech. Des. (ASME) 102:4 (1980), 793-803.

[Nelson 2003] F. C. Nelson, "A brief history of early rotor dynamics", Sound Vib. 37:6 (2003), 8-11.

[Ruhl and Booker 1972] R. L. Ruhl and J. F. Booker, "A finite element model for distributed parameter turborotor systems", $J$. Eng. Ind. (ASME) 94:1 (1972), 126-132.

[Vinod et al. 2007] K. G. Vinod, S. Gopalakrishnan, and R. Ganguli, "Free vibration and wave propagation analysis of uniform and tapered rotating beams using spectrally formulated finite elements”, Int. J. Solids Struct. 44:18-19 (2007), 5875-5893. 
[Wittrick and Williams 1971] W. H. Wittrick and F. W. Williams, "A general algorithm for computing natural frequencies of elastic structures", Q. J. Mech. Appl. Math. 24:3 (1971), 263-284.

[Zu and Han 1992] J. W.-Z. Zu and R. P. S. Han, "Natural frequencies and normal modes of a spinning Timoshenko beam with general boundary conditions”, J. Appl. Mech. (ASME) 59:2S (1992), S197-S204.

Received 18 Apr 2011. Revised 23 Jun 2011. Accepted 23 Jun 2011.

UsIK LEE: ulee@inha.ac.kr

Department of Mechanical Engineering, Inha University, 253 Yonghyun-Dong, Nam-Gu, Incheon 402-751, South Korea INJOON JANG: injoonjang@inha.edu

Department of Mechanical Engineering, Inha University, 253 Yonghyun-Dong, Nam-Gu, Incheon 402-751, South Korea 


\title{
JOURNAL OF MECHANICS OF MATERIALS AND STRUCTURES
}

\author{
jomms.net
}

\author{
Founded by Charles R. Steele and Marie-Louise Steele \\ EDITORS \\ Charles R. STEele \\ DAVIDE BIGONI \\ Stanford University, USA \\ University of Trento, Italy \\ IWONA JASIUK University of Illinois at Urbana-Champaign, USA \\ YASUHIDE SHINDO Tohoku University, Japan
}

\section{EDITORIAL BOARD}

H. D. Bui École Polytechnique, France

J. P. CARTER University of Sydney, Australia

R. M. CHRISTENSEN Stanford University, USA

G. M. L. GLadWELL University of Waterloo, Canada

D. H. Hodges Georgia Institute of Technology, USA

J. HUTCHINSON Harvard University, USA

C. HwU National Cheng Kung University, Taiwan

B. L. KARIHALOO University of Wales, UK

Y. Y. KIM Seoul National University, Republic of Korea

Z. Mroz Academy of Science, Poland

D. PAmplona Universidade Católica do Rio de Janeiro, Brazil

M. B. RUBIN Technion, Haifa, Israel

A. N. SHUPIKOV Ukrainian Academy of Sciences, Ukraine

T. TARNAI University Budapest, Hungary

F. Y. M. WAN University of California, Irvine, USA

P. WRIGGERS Universität Hannover, Germany

W. YANG Tsinghua University, China

F. ZIEGLER Technische Universität Wien, Austria

PRODUCTIONｃontact@msp.org

Silvio LEVY Scientific Editor

See http://jomms.net for submission guidelines.

JoMMS (ISSN 1559-3959) is published in 10 issues a year. The subscription price for 2012 is US $\$ 555 /$ year for the electronic version, and \$735/year (+\$60 shipping outside the US) for print and electronic. Subscriptions, requests for back issues, and changes of address should be sent to Mathematical Sciences Publishers, Department of Mathematics, University of California, Berkeley, CA 94720-3840.

JoMMS peer-review and production is managed by EditFLOw ${ }^{\circledR}$ from Mathematical Sciences Publishers.

\author{
mathematical sciences publishers \\ http://msp.org/ \\ A NON-PROFIT CORPORATION \\ Typeset in $\mathrm{IAT}_{\mathrm{E}} \mathrm{X}$ \\ Copyright $@ 2012$ by Mathematical Sciences Publishers
}




\title{
Journal of Mechanics of Materials and Structures
}

\author{
Volume 7, No.2 February 2012
}

Micromechanical analysis of unidirectional composites using a least-squares-based differential quadrature element method

Mohammad Bayat and Mohammad Mohammadi Aghdam

Size-dependent free vibration analysis of infinite nanotubes using elasticity theory

JAFAR ESKandari JaM, YASER Mirzaei, Behnam GHeShlaghi

and ReZa AvaZmohammadi

Spectral element model for the vibration of a spinning Timoshenko shaft

USIK LEE and INJOON JANG

On indenter boundary effects at elastic contact

Denis Jelagin and Per-Lennart LaRsson 165

Reflection of $P$ and $S V$ waves from the free surface of a two-temperature thermoelastic solid half-space

BALJEET SingH and KirAN BALA

A nonlinear Timoshenko beam formulation based on strain gradient theory ReZa Ansari, RAHEb GHOLAmi and MOHAMMAD ALI DARABi

Finite element analysis of bending-stiff composite conical shells with multiple delamination 